\title{
In situ generated D-peptidic nanofibrils as multifaceted apoptotic inducers to target cancer cells
}

\author{
Xuewen Du', Jie Zhou ${ }^{1}$, Huainin Wang ${ }^{1}$, Junfeng Shi ${ }^{1}$, Yi Kuang ${ }^{1}$, Wu Zeng ${ }^{2}$, Zhimou Yang ${ }^{3}$ and Bing Xu ${ }^{*}, 1$
}

Nanofibrils of small molecules, as a new class of biofunctional entities, exhibit emergent properties for controlling cell fates, but the relevant mechanism remains to be elucidated and the in vivo effect has yet to be examined. Here, we show that D-peptide nanofibrils, generated by enzyme-instructed self-assembly (EISA), pleiotropically activate extrinsic death signaling for selectively killing cancer cells. Catalyzed by alkaline phosphatases and formed in situ on cancer cells, D-peptide nanofibrils present autocrine proapoptotic ligands to their cognate receptors in a juxtacrine manner, as well as directly cluster the death receptors. As multifaceted initiators, D-peptide nanofibrils induce apoptosis of cancer cells without harming normal cells in a co-culture, kill multidrug-resistant (MDR) cancer cells, boost the activities of anticancer drugs, and inhibit tumor growth in a murine model. Such a supramolecular cellular biochemical process (consisting of reaction, assembly, and binding) for multi-targeting or modulating protein-protein interaction networks ultimately may lead to new ways for combating cancer drug resistance.

Cell Death and Disease (2017) 8, e2614; doi:10.1038/cddis.2016.466; published online 16 February 2017

Kinases and phosphatases regulate phosphorylation and dephosphorylation, ${ }^{1,2}$ respectively, and control a variety of cellular processes. Kinase inhibitors have achieved relative successes in chemotherapy, but the development of phosphatases inhibitors remains to be a challenge. Since a number of phosphatases (e.g., $\mathrm{PTEN}^{3}$ ) are important tumor suppressors, the lack of selectivity of phosphatase inhibitors is a major concern. The inherent difficulty for developing specific phosphatase inhibitors has earned phosphatases the reputation of undruggable. ${ }^{4}$ Thus, new approaches to make phosphatases druggable are needed. Departing from the dogmatic approach of enzyme inhibition, we have been exploring the use of alkaline phosphatase (ALP) to catalyze the formation of molecular nanofibrils via self-assembly ${ }^{5,6}$ for killing cancer cells. ${ }^{7-12}$ The merit is that nanofibrils of small molecules, spatiotemporally defined by enzymatic catalysis and self-assembly (i.e., EISA), can interact with multiple cellular proteins and interrupt multiple cellular processes to kill cancer cells selectively, ${ }^{13,14}$ even without inducing acquired drug resistance. ${ }^{13}$ After we demonstrated that EISAgenerated nanofibrils selectively kill cancer cells, ${ }^{15,16}$ several labs have already validated this concept of EISA in cell assays. ${ }^{17,18}$ However, the relevant molecular and cellular mechanisms of cell death induced by the nanofibrils remain to be elucidated, and the in vivo effects of the nanofibrils generated by EISA have yet to be examined.

Here, we report the mechanistic study of using ALP catalysis, not ALP inhibition, to generate molecular nanofibrils for selectively killing cancer cells. Specifically, ALP, as an ectoenzyme, ${ }^{19}$ catalyzes the formation of pericellular nanofibrils of D-tripeptides (DTPs) on cancer cells, which pleiotropically activate cell death signaling by presenting autocrine death ligands (e.g., TNF- $a^{20}$ and TRAIL ${ }^{21}$ ) to their cognate receptors (e.g., TNFR1/2, DR3/4/5) $)^{22}$ in a juxtacrine manner, ${ }^{23}$ as well as directly clustering the receptors (e.g., $\left.C D 95^{24}\right)$. As the localized multifaceted initiators, DTP nanofibrils induce apoptosis. ${ }^{25}$ The ALP-generated DTP nanofibrils kill cancer cells without harming normal cells in a mimicked tumor microenvironment, ${ }^{26}$ kill multidrug-resistant (MDR) cancer cells, boost the activities of anticancer drugs (e.g., cisplatin $^{27}$ and NF- $k$ B inhibitors ${ }^{28,29}$ ), and inhibit tumor growth in a murine model. These results demonstrate a paradigm shift from inhibition to reaction, that is, the use of a multiple step - reaction, assembly, and binding - process $^{30}$ to modulate protein-protein interaction networks for selectively killing cancer cells.

\section{Results and Discussion}

ALP-generated nanofibrils for killing HeLa cells in a coculture. Since certain ALP (e.g., placental alkaline phosphatase (PLAP) on HeLa cells ${ }^{31}$ ) is overexpressed on the surface of certain cancer cells in the co-culture (mixture of cancer (HeLa) and normal (HS-5) cells), the precursor of DTP (i.e., a phosphorylated DTP, pDTP) is dephosphorylated locally on the surface of the cancer cells to generate DTP nanofibrils (Figure 1a). Acting as a pericellular nanonet just around the cancer cells, the DTP nanofibrils present the secreted, different proapoptotic ligands (e.g., TNF- $a$, CD95L, and TRAIL) from cancer cells to bind with different extrinsic cell death receptors (e.g., TNFR1/2, CD95, and DR3/4/5), or directly interact with the death receptors (e.g., CD95), which leads to the death of cancer cells only. Multiple evidences in

${ }^{1}$ Department of Chemistry, Brandeis University, Waltham, MA 02454, USA; ${ }^{2}$ The Heller School for Social Policy and Management, Brandeis University, Waltham, MA 02454, USA and ${ }^{3}$ The College of Life Sciences, Nankai University, Tianjin 300071, China

*Corresponding author: B Xu, Department of Chemistry, Brandeis University, 415 South Street, Waltham, MA 02454, USA. Tel: 7817365 201; Fax: 7817362516 ; E-mail: bxu@brandeis.edu

Received 18.8.16; revised 28.11.16; accepted 30.11.16; Edited by J Chipuk 
the following sections support the mechanism illustrated in Figure 1a.

Adding ALP to the solution of pDTP (Figure $1 \mathrm{~b}$ ) results in DTP nanofibrils (Figure 1c) (diameters of $7 \pm 2 \mathrm{~nm}$ ), indicating that ALP overexpressed on the cancer cells can generate DTP nanofibrils. Adding pDTP in the co-culture of HeLa and HS-5 (as a mimic of tumor microenvironment ${ }^{26}$ ) selectively kills the cancer cells (HeLa-GFP ${ }^{32}$ ) in the co-culture (Figure 1d and

a in situ assembly
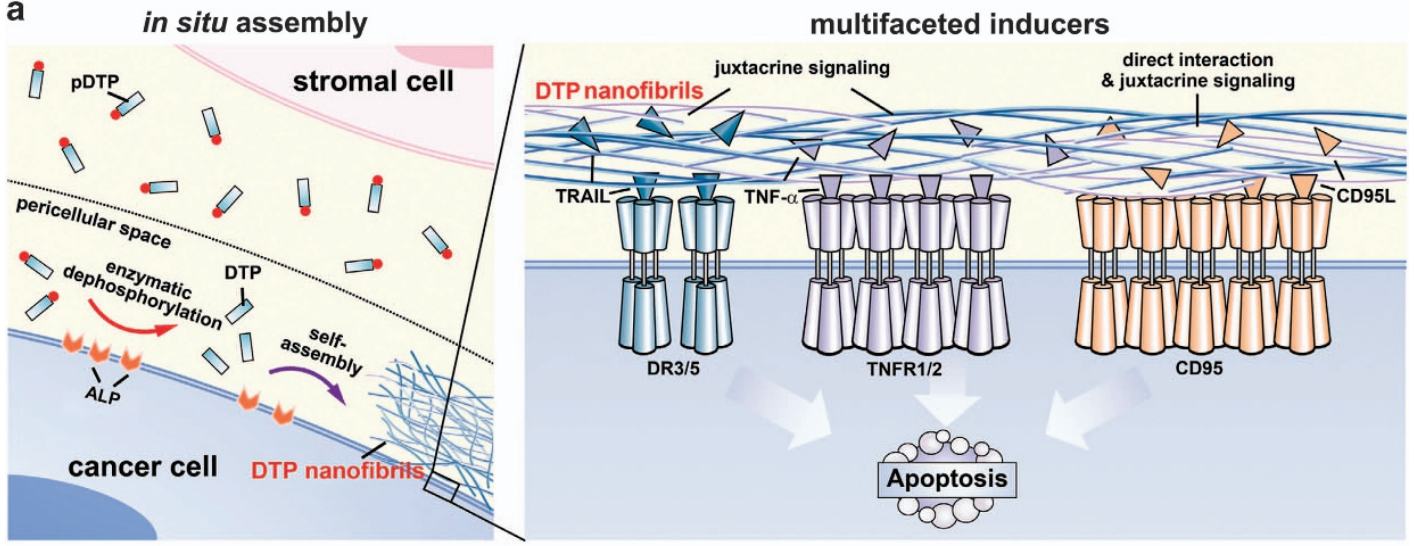

b

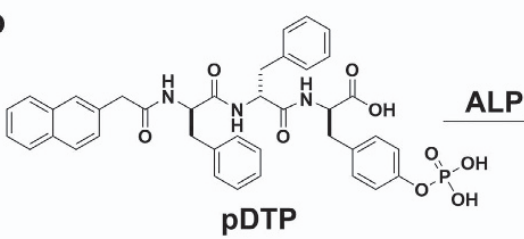<smiles>O=C(Cc1ccc2ccccc2c1)NC(Cc1ccccc1)C(=O)N[C@@H](Cc1ccccc1)C(=O)N(Cc1ccc(O)cc1)C(=O)Cc1ccccc1</smiles>

C DTP nanofibrils

d

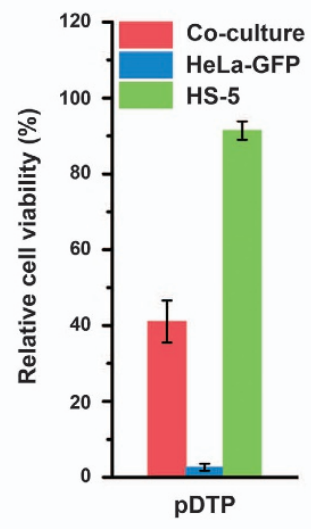

g

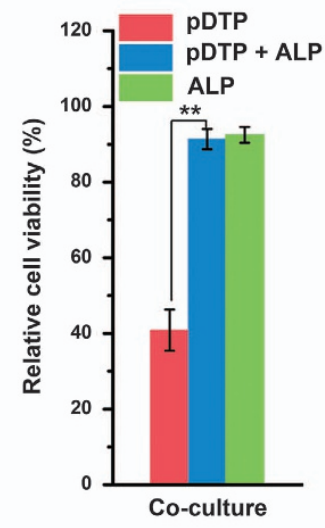

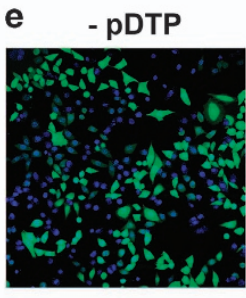
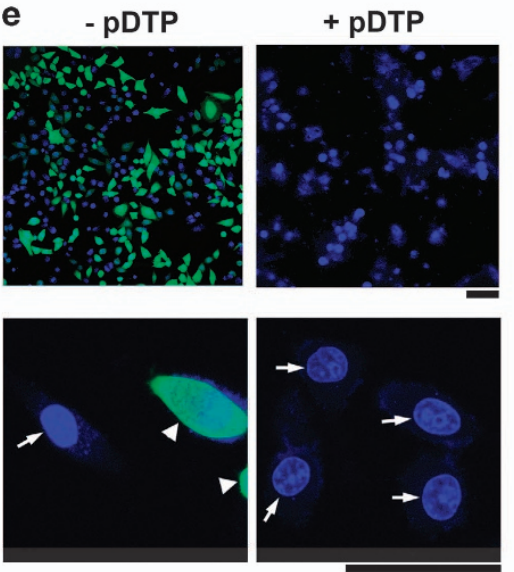

h Hoechst
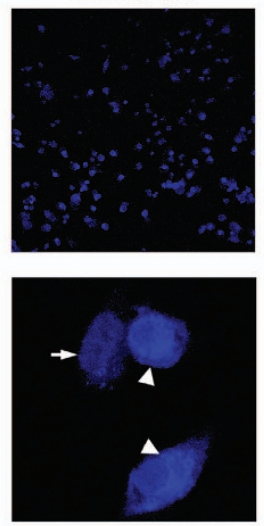

GFP f
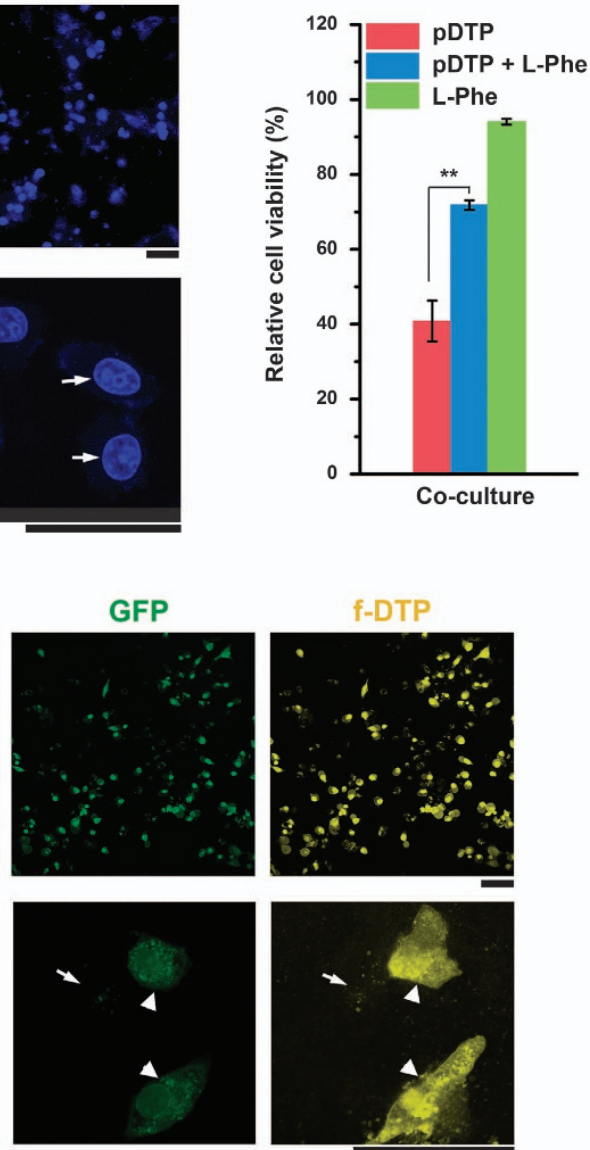

f-DTP
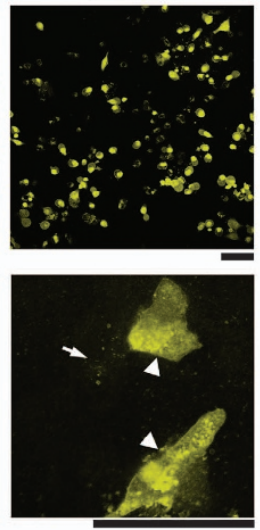
Supplementary Figure 1a), agreeing with the results in their separated cultures (Supplementary Table 1). As shown in the fluorescent imaging (Figure 1e and Supplementary Figure 1b) of the co-culture treated with pDTP, contrasting to the control, almost no HeLa-GFP cells live, while the HS-5 cells remain viable. The addition of L-phenylalanine (L-Phe), an uncompetitive inhibitor of PLAP, ${ }^{33}$ almost doubles the viability of HeLaGFP cells, in comparison with only pDTP in culture medium (Figure 1f and Supplementary Figure 1c), excluding the possibility that pDTP acts as surfactants to lyse cells and confirming that PLAP on HeLa cells catalyzes the EISA of pDTP to selectively kill cancer cells. siRNA knock-down of PLAP on HeLa cells protects the cells from pDTP, confirming that PLAP is essential for killing HeLa cells (Supplementary Figure 1e) by EISA. Simultaneous addition of exogenous ALP with pDTP abrogates the cytotoxicity of pDTP (Figure $1 \mathrm{~g}$ and Supplementary Figure 1d). Meanwhile, we design a fluorescent pDTP (f-pDTP) (Supplementary Figures $2 a$ and b), which is innocuous to cells (likely due to f-DTP resulting in nanofibrils different from DTP nanofibrils) (Supplementary Figure 2c), for imaging the peptidic nanofibrils in the co-culture. The bright yellow fluorescence, resulted from the nanofibrils of f-DTP, mainly localizes on HeLa-GFP cells, and only few fainted yellow dots in HS-5 cells (Figure $1 \mathrm{~h}$ and Supplementary Figure 2d). Collectively, these results confirm that ALPS, as ectoenzymes overexpressed on cancer cells, generate DTP nanofibrils in situ for selectively killing cancer cells without harming normal cells.

ALP-generated nanofibrils pleiotropically activate extrinsic death signaling. We focus on extrinsic cell death signaling because previous results suggest the ALPgenerated DTP nanofibrils inducing mitochondrial independent cell death. ${ }^{7}$ Co-incubating zVAD-fmk ${ }^{34}$ (a pan-caspase inhibitor) with pDTP significantly reduces the cell death (Figure 2a), indicating that DTP nanofibrils mainly induce apoptosis. We co-incubate pDTP with extrinsic cell death ligands and monoclonal antibodies (mAbs) of key extrinsic cell death signaling molecules, respectively. While anti-TNF- $a$ considerably protects cells, anti-TNFR1 or anti-TNFR2 leads to more cell death (Figure $2 \mathrm{~b}$ and Supplementary Figures $3 a-c)$. hTNF- $a$ also causes more cell death without the use of cycloheximide $^{35}$ (Supplementary Figure 3d). These results indicate that DTP nanofibrils enhance interactions between the autocrine TNF- $a^{36}$ and its cognate receptors, likely by presenting TNF- $a$ in a juxtacrine manner. ${ }^{37}$ siRNA knockdown $^{38}$ of TNFR1 or TNFR2 in HeLa cells decreases the cytotoxicity of pDTP (Figure $2 \mathrm{~b}$ and Supplementary Figure 3I), agreeing with the juxtacrine presentation of TNF-a (as well as anti-TNFR1 or anti-TNFR2) by DTP nanofibrils (Figure 1a). While anti-DR5 exhibits little effect, anti-DR3, anti-DR4, or TRAIL slightly promotes cell death (Figure 2c and Supplementary Figures 3e, 3f, and 3h). AntiTRAIL only slightly decreases the cytotoxicity of DTP nanofibrils (Supplementary Figure $3 \mathrm{~g}$ ), but knock-down of DR3 or DR5 considerably rescues the cells (Supplementary Figure 3I). These results suggest that DTP nanofibrils, besides interacting with TRAILRs via the juxtacrine presentation of TRAIL, directly interact with TRAILRs. Either antiCD95 or CD95L improves the cell survival, anti-CD95L results in more cell death (Figure $2 \mathrm{~d}$ and Supplementary Figure 3i-k), and knock-down of CD95 decreases the cytotoxicity of pDTP (Supplementary Figure 3l). These results indicate that DTP nanofibrils directly interact with CD95 to cause apoptosis (Figure 1a). Although the siRNA knock down of two cell death receptors simultaneously (e.g., CD95 and TNFR1, CD95 and TNFR2, or TNFR1 and TNFR2) is less effective than the knock down of one death receptor, it still protects HeLa cells from DTP nanofibrils (Supplementary Figures $3 m-p)$ at certain extent.

After the addition of pDTP, primary mAbs of death receptors, and the fluorescent secondary $\mathrm{mAb}$, cell imaging reveals significantly increased clustering of CD95 and moderately induced aggregation of TNFR2 and DR3 (Figure 2e and Supplementary Figures $4 \mathrm{a}-\mathrm{c}$ ), agreeing with clustering the death receptors as a key feature of apoptosis signaling. ${ }^{39}$ Together with the integrated intensity of fluorescence (Figure 2f), these results further support the mechanism in Figure 1a. As the controls, anti-TNFR1 or anti-TNFR2 coincubating with DTP in HeLa culture (Supplementary Figure 5a) or with pDTP in HS-5 culture (Supplementary Figure $5 b$ ) exhibits little effect on cell viabilities, confirming that ALP in situ generating DTP nanofibrils is the critical process for selective inhibition of cancer cells (Figure 1a). Moreover, The knock-downed death receptors (i.e., TNFR2, CD95, or DR5) re-emerge (Figure $2 \mathrm{~g}$ ) after incubating the siRNAtreated HeLa cells with pDTP, suggesting that DTP nanofibrils interact with other unknock-downed death receptors to induce the re-emergence, likely via molecular crosstalk between cell death and survival signaling. ${ }^{40}$

Figure 1 Enzyme in situ generates pericellular D-peptide nanofibrils for selectively inhibiting cancer cells in co-culture. (a) The illustration of the pericellular DTP nanofibrils formed by enzyme-instructed self-assembly (EISA) to selectively inhibit cancer cells in co-culture via promiscuously activating cell death signaling. (b) Chemical structures of the precursor (pDTP), the self-assembly tripeptide (DTP), and the dephosphorylation of the precursor catalyzed by PLAP. (c) Transmission electron microscopic (TEM) images of DTP nanofibrils formed by the addition of alkaline phosphatase $(5 \mathrm{U} / \mathrm{ml})$ to the solution of pDTP at the concentration of $362 \mu \mathrm{g} / \mathrm{ml}$. (d) Relative cell viability of the co-cultured cells (HS-5 and HeLa-GFP cells), HeLa-GFP, or HS-5 incubated with pDTP. The initial number of cells is $1.0 \times 10^{4} /$ well (e.g., $1.0 \times 10^{4}$ HeLa-GFP or HS- 5 cells, or mixture of $5.0 \times 10^{3}$ HeLa-GFP cells and $5.0 \times 10^{3} \mathrm{HS}-5$ cells) and [pDTP] $=216 \mu \mathrm{g} / \mathrm{ml}$. (e) The fluorescent images of low (top) or high (bottom) magnification of co-cultured cells incubated with or without pDTP $(362 \mu \mathrm{g} / \mathrm{ml})$ for $48 \mathrm{~h}$. Blue indicates all the live cells stained by Hoechst $33342(1 \mu \mathrm{g} / \mathrm{ml}, 5 \mathrm{~min})$ before fluorescent imaging; green indicates the live HeLa-GFP cells. The initial number of cells is $1.0 \times 10^{5} /$ well. Relative cell viability of the co-cultured HS-5 and HeLa-GFP cells (f) incubated with pDTP, pDTP+L-Phe, or L-Phe, or (g) incubated with pDTP, pDTP+AP, or AP in DMEM for $48 \mathrm{~h}$. The initial number of cells is $1.0 \times 10^{4} / \mathrm{well}$ and $[\mathrm{pDTP}]=216 \mu \mathrm{g} / \mathrm{ml},[\mathrm{L}-\mathrm{Phe}]=1.0 \mathrm{mM},[\mathrm{AP}]=0.1 \mathrm{U} / \mathrm{ml}$. $n=3$. Data are shown as mean \pm S.D. ${ }^{*} P<0.05,{ }^{* *} P<0.01$ by Student's $t$-test. (h) The fluorescent images of low (top) or high (bottom) magnification of co-cultured cells incubated with f-pDTP (493 $\mu \mathrm{g} /$ $\mathrm{ml}$ ) for $4 \mathrm{~h}$. Blue indicates all the live cells stained by Hoechst 33342; green indicates the live HeLa-GFP cells; and yellow indicates the peptide nanofibrils of f-DTP. The initial number of cells is $1.0 \times 10^{5} /$ well. The scale bars are $100 \mathrm{~nm}$ in (c), $100 \mu \mathrm{m}$ in (top of (e) and (h)), $50 \mu \mathrm{m}$ in (bottom of (e) and (h)). Bottom row of (e) and (h): white arrows point at HS-5, and arrow heads at HeLa-GFP 
a

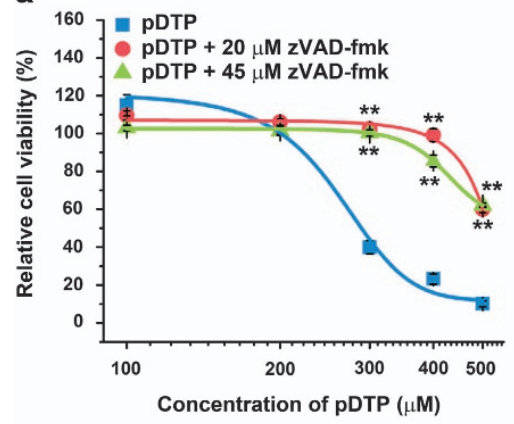

d

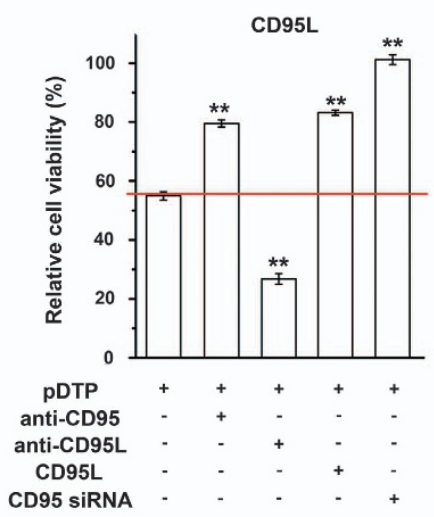

f

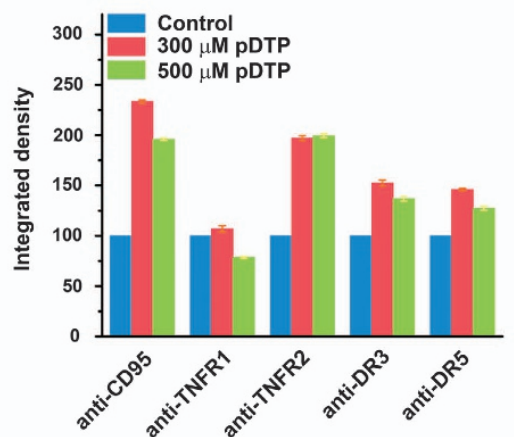

b

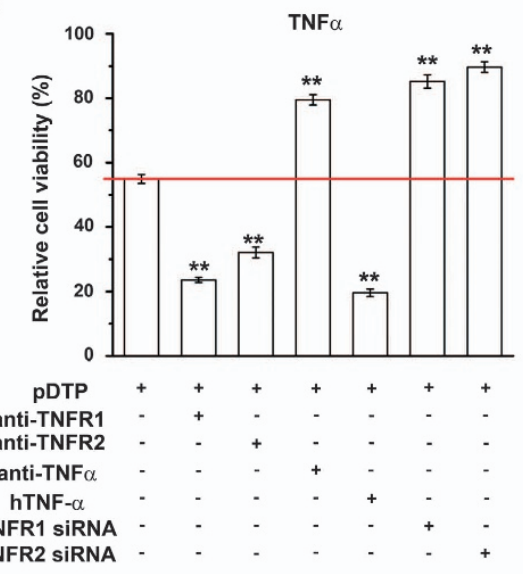

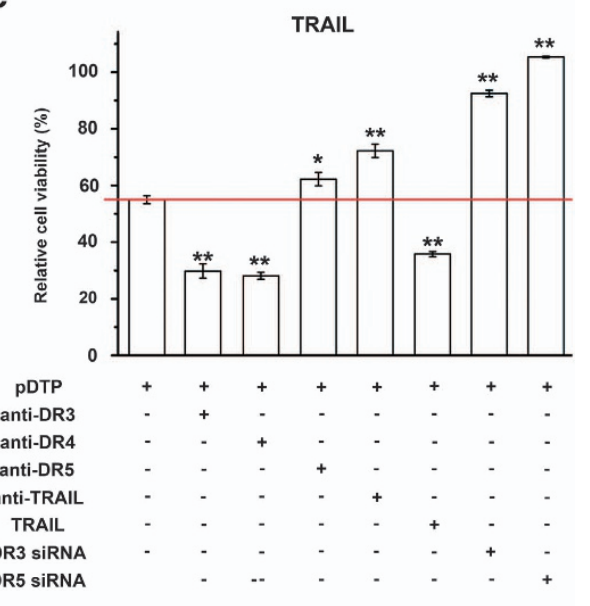

e

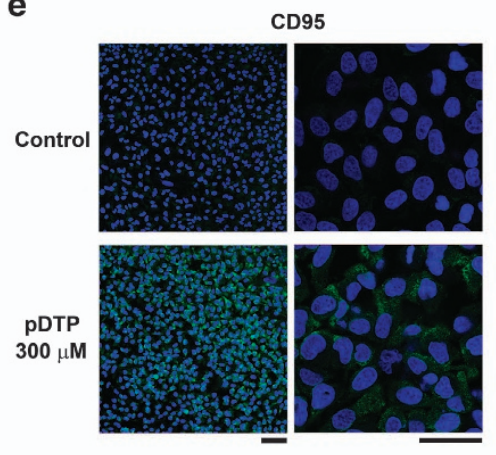

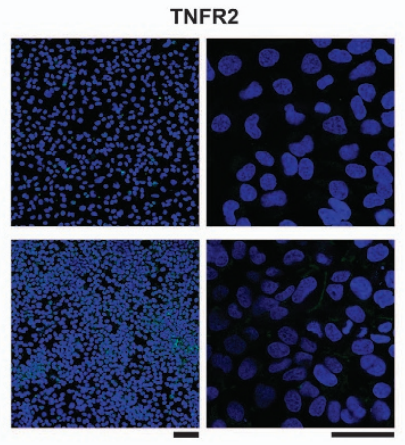

g

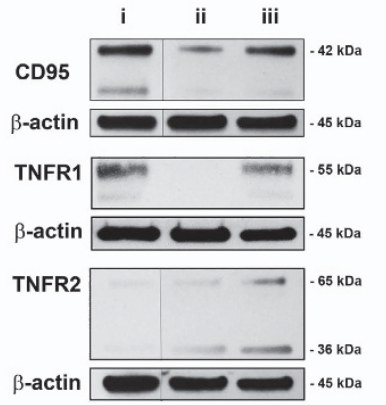

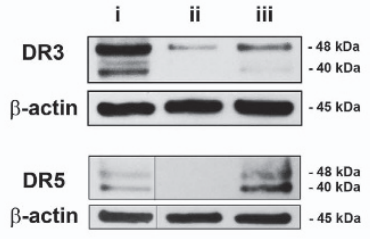

i: HeLa cells treated with control siRNA ii: Knock-down HeLa cells;

iii: Knock-down HeLa cells treated with pDTP.

Figure 2 Pericellular D-peptide nanofibrils act as multifaceted inducer of apoptosis. (a) Relative cell viability of HeLa cells treated with different concentrations of pDTP and 20 or $45 \mu \mathrm{M}$ of pan-caspase inhibitor zVAD-fmk for $48 \mathrm{~h}$. The initial number of cells is $1.0 \times 10^{4} /$ well. $n=3$. Relative cell viability of HeLa cells treated with $300 \mu \mathrm{M}$ pDTP and (b) TNF$\alpha$-related mAbs; (c) TRAlL-related mAbs; or (d) CD95L-related mAbs for $48 \mathrm{~h}$. Data are shown as mean \pm S.D. ${ }^{*} P<0.05,{ }^{\star \star} P<0.01$ by Student's $t$-test. (e) The overlaid confocal fluorescent microscope images ( $\times 20$ dry (left) or $\times 100$ oil (right) objective lens) show the clustering of the cell death receptors. Cells are treated with death receptor antibodies (e.g., anti-CD95 or anti-TNFR2 mAb) and growth medium (control) or $300 \mu \mathrm{M}$ of pDTP in growth medium. Blue indicates all the live cells stained by Hoechst 33342 at the concentration of $1 \mu \mathrm{g} / \mathrm{ml}$; and green indicates the secondary antibodies. The initial number of cells is $1.0 \times 10^{5} /$ well. The scale bar is $100 \mu \mathrm{m}$ for low magnification (left) and $50 \mu \mathrm{m}$ for high magnification (right). (f) The quantification of integrated density of fluorescence of HeLa cells treated with $300 \mu \mathrm{M}$ or $500 \mu \mathrm{M}$ of pDTP in growth medium and the cell death receptor mAbs. (g) Western blot shows the expression of death receptors (i.e., CD95, TNFR1, TNFR2, DR3, and DR5) in HeLa cells treated with control siRNA, knock-down HeLa cells, or knock-down HeLa cells treated with $300 \mu \mathrm{M}$ of pDTP for $24 \mathrm{~h}$

We compare the amounts of secreted extrinsic cell death ligands trapped in the pericellular DTP nanofibrils and those in the conditioned medium of HeLa cells and find that DTP nanofibrils retain little TRAIL, a moderate level of TNF- $a$, and CD95L significantly (Figure 3a). Although the cell lysate of HeLa contains TNF- $a$, TRAIL, and CD95L (Figure 3b), only CD95L exhibits the considerably high amount in the pericellular DTP nanofibrils, agreeing with that cancer cells, under stress, increase the secretion of CD95L. This result further supports that DTP nanofibrils present the autocrine death ligands (Figure $3 b$ ). In addition, the western blot reveals that pDTP exhibits little effect on the expression of TNF- $a$ or TRAIL while moderately increases the expression of CD95L (Supplementary Figure $5 \mathrm{~h}$ ), suggesting that the pericellular DTP nanofibrils, besides increasing autocrine CD95 L o HeLa cells, mainly retain the autocrine death ligands near the cell 
a

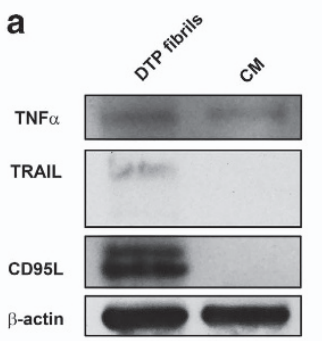

b

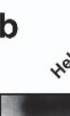

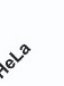

$38 \mathrm{kDa}$

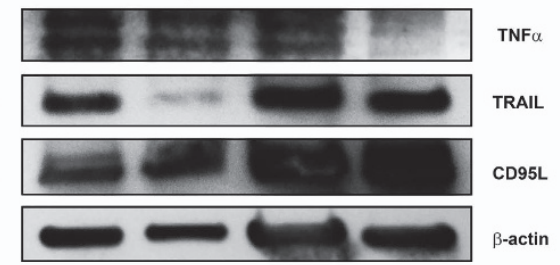

d

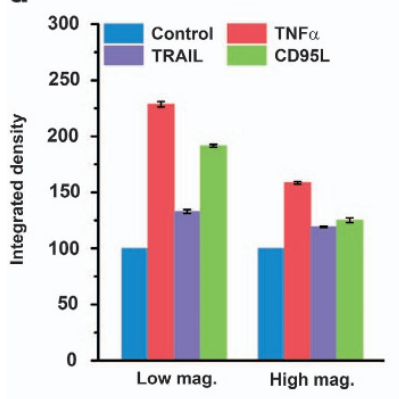

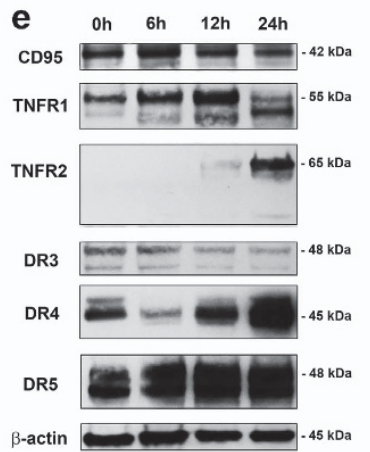

f oh $6 \mathrm{~h} \quad 12 \mathrm{~h} \quad 24 \mathrm{~h}$
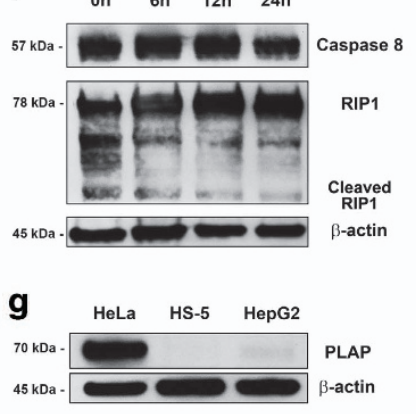
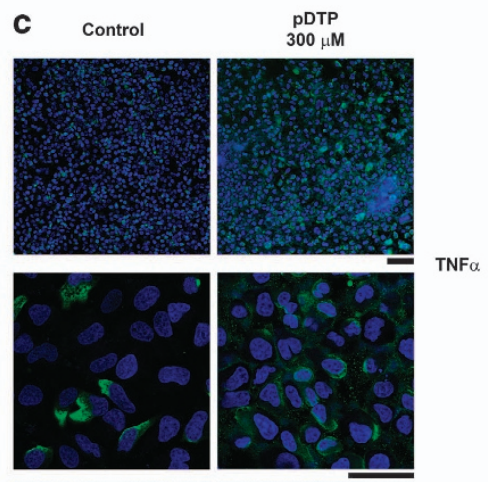

TNF $\alpha$
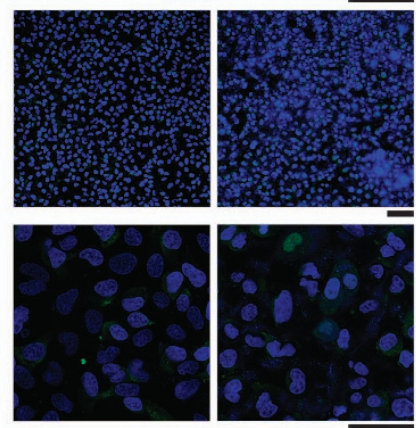

TRAIL
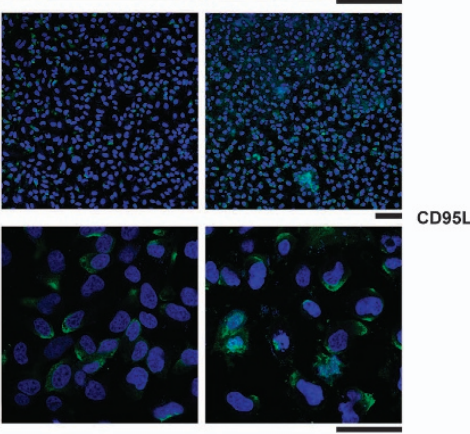

j

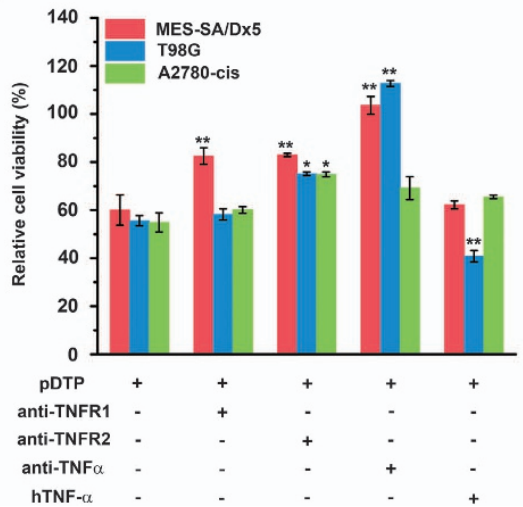

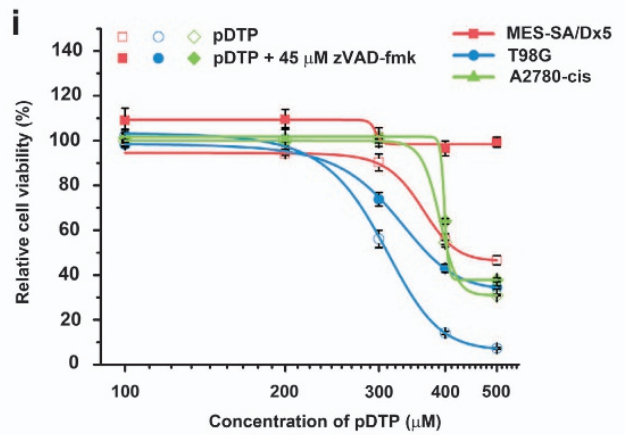

k

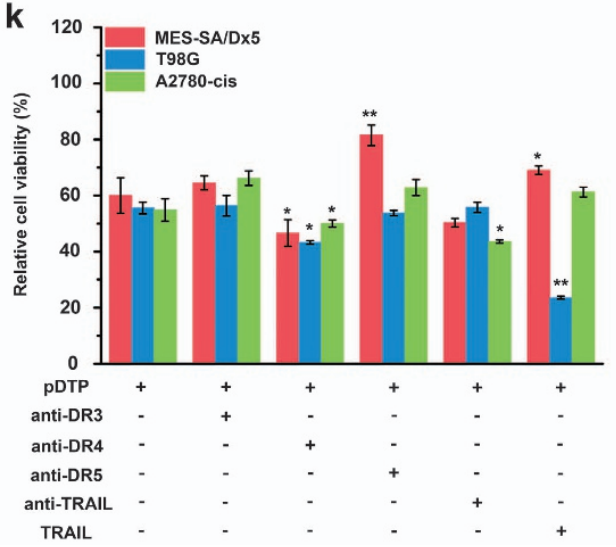

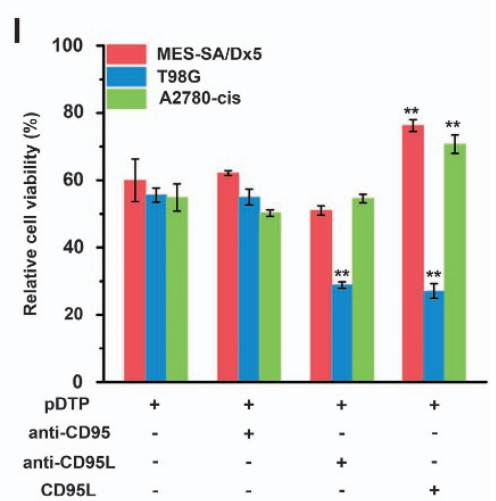

Figure 3 Pericellular D-peptide nanofibrils selectively inhibit cancer cells in co-culture via presenting autocrine death ligands, and act as a multifaceted death signal of the apoptosis of cancer cells. Western blot shows the difference of death ligands (a) in pericellular DTP nanofibrils and conditioned medium (CM) with HeLa cells; (b) in four kinds of cell lysates (i.e., HeLa, MES-SA/Dx5, T98G, A2780-cis). (c) Fluorescent images show the expression of cell death ligands. Blue indicates all the live cells stained by Hoechst 33342; and green indicates the secondary antibodies. The initial number of cells is $1.0 \times 10^{5} /$ well. The scale bar is $100 \mu \mathrm{m}$ for low magnification (up) and $50 \mu \mathrm{m}$ for high magnification (down). (d) The quantification of integrated density of fluorescence of HeLa cells showed in c. Western blot shows change of relative amount of (e) cell death receptors; (f) down-stream proteins over time in HeLa cells treated by $300 \mu \mathrm{M}$ of pDTP. (g) Western blot shows the difference of PLAP expressed on membrane of three kinds of cells (i.e., HeLa, HS-5, HepG2). (h) Relative cell viability of the co-cultured cells (HS-5 and MDR cancer cells) incubated with pDTP in DMEM for $48 \mathrm{~h}$. The initial number of cells is $1.0 \times 10^{4} /$ well (e.g., $1.0 \times 10^{4} \mathrm{MDR}$ or HS- 5 cells, or mixture of $5.0 \times 10^{3} \mathrm{MDR}$ cells and $5.0 \times 10^{3} \mathrm{HS}-5$ cells). (i) Relative cell viability of MDR cells treated with pDTP and zVAD$\mathrm{fmk}$ for $48 \mathrm{~h}$. Relative cell viability of MDR cells treated with 400 or $500 \mu \mathrm{M} \mathrm{pDTP}$ and (j) TNF- $\alpha$-related mAbs; (k) TRAIL-related mAbs; or (I) CD95L-related mAbs for $48 \mathrm{~h}$. The initial number of cells is $1.0 \times 10^{4} /$ well. $n=3$. Data are shown as mean \pm S.D. ${ }^{*} P<0.05,{ }^{*} P<0.01$ by Student's $t$-test 
surface to interact with the death receptors. However, it is also possible that DTP nanofibrils possess slightly higher affinity to CD95L and CD95 than to TNF- $a$ and TRAIL. Nevertheless, the fluorescent imaging of HeLa cells treated with pDTP, primary mAbs of the ligands, and the fluorescent secondary mAb (Figure 3c), together with quantification of the fluorescence (Figure 3d), indicates that the pericellular DTP nanofibrils increase the clustering of death ligands (e.g., TNF- $a$, CD95L), which is consistent with that DTP nanofibrils present the autocrine proapoptotic ligands to their cognate receptors in a juxtacrine manner.

To further confirm that DTP nanofibrils are able to present the death ligands, we test the effect of pDTP on CD95L-KO HeyA8 cells (Supplementary Figure $5 c$ ). pDTP only exhibits weak cytotoxicity to CD95L-KO HeyA8 cells at $48 \mathrm{~h}$. But the addition of CD95L together with pDTP significantly increases the CD95L-KO HeyA8 cell death. This result supports the notion that DTP nanofibrils present CD95L to induce apoptosis.

For the pDTP-treated HeLa cells, Western blot reveals that, while the constitutive expression of TNFR1 increases initially and then decreases moderately, the inductive expression of TNFR2, especially the glycosylated form (75 kD), ${ }^{41}$ significantly increases over time. While the expressions of CD95 and DR3 decrease slightly, expression of DR4 increases remarkably, and expression of DR5 increases moderately (Figure 3e). None of these changes of TNFR1 and TNFR2 occur in the controls (Supplementary Figures $5 d-g$ ), confirming that the ALP-generated DTP nanofibrils result in those changes. Western blot of the down-stream proteins (e.g., caspase 8 or RIP1) shows that pDTP slightly decreases the expression of caspase 8 and the cleaved RIP1 while increases expression of RIP1 (Figure 3f), agreeing with that DTP nanofibrils mainly result in apoptosis. In the case of HeLa cells, we find that cleaved caspase 8 appears at $24 \mathrm{~h}$, cleaved caspase 3 emerges around $36 \mathrm{~h}$, and cleaved PARP also arises in small amount at $12 \mathrm{~h}$ and is significantly produced around $24 \mathrm{~h}$. These results (Supplementary Figure 5i) confirm DTP nanofibrils activate caspases for apoptosis of HeLa cells. In addition, HeLa cells overexpress PLAP on membrane, while HS-5 and HepG2 cells barely express PLAP (Figure $3 g$ ). This fact, together with the cell viabilities of these three cells treated by pDTP (Supplementary Table 1), suggests that pDTP acts as the substrate of ALP (e.g., PLAP) on HeLa cells to form the nanofibrils that induce apoptosis. These results demonstrate DTP nanofibrils as multifaceted inducers of apoptosis by pleiotropically interacting with extrinsic cell death ligands and receptors.

\footnotetext{
ALP-generated nanofibrils selectively kill MDR cancer cells. As shown by western blot (Supplementary Figure 6a), several MDR cancer cells (e.g., MES-SA/Dx5, T98G, and A2780-cis) also overexpress ALPs. Besides overexpressing germ cell alkaline phosphatases, MES-SA/Dx5, T98G, and A2780cis overexpress tissue non-specific alkaline phosphatases. So we evaluate the responses of these three MDR cells to pDTP, including in their co-cultures with HS-5, and examine the corresponding cell death mechanisms. pDTP selectively induces apoptosis of those MDR cancer cells while remains innocuous to HS-5 cells in their co-cultures
}

(Figure 3h and Supplementary Figure 6b), agreeing with the viability results in their separated cultures (Supplementary Table 1). zVAD-fmk, co-incubated with pDTP, almost completely rescues MES-SA/Dx5, significantly protects T98G, and moderately reduces the death of A2780-cis (Figure 3i), indicating that DTP nanofibrils induce apoptosis of those cells, albeit at different extent. hTNF- $a$ leads to more death of T98G than those of MES-SA/Dx5 and A2780-cis; anti-TNF- $a$ significantly protects MES-SA/Dx5 and T98G, anti-TNFR1 rescues MES-SA/Dx5; anti-TNFR2 moderately protects MES-SA/Dx5, T98G, and A2780-cis (Figure 3j and Supplementary Figure 6c). TRAIL results in more death of T98G, but offers slight protection to MES-SA/Dx5 and A2780-cis; anti-TRAIL slightly promotes the death of MES-SA/Dx5 and A2780-cis; anti-DR3 slightly protects MES-SA/Dx5; anti-DR4 slightly increases cytotoxicity of all the three cells; antiDR5 mainly protects MES-SA/Dx5 (Figure 3k and Supplementary Figure $6 \mathrm{~d}$ ). CD95L also causes more death of T98G, but offers considerable protection to MES-SA/Dx5 and A2780-cis; anti-CD95L only leads more death of T98G; antiCD95 hardly affects MES-SA/Dx5, T98G, and A2780-cis cells (Figure $3 \mathrm{I}$ and Supplementary Figure 6e). Both antiCD95L and CD95L increase cell death of T98G, indicating that the pericellular DTP nanofibrils may directly interact with CD95 receptors as well as present autocrine CD95L of T98G cells. These apparently paradoxical results reflect the complexity and versatility of the EISA process and molecular nanofibrils. These results indicate that DTP nanofibrils directly interact with CD95 and DR5 or present TNF- $a$ to induce death of MES-SA/Dx5 and A2780-cis, but mainly present TNF- $a$, TRAIL, and CD95L to their cognate receptors inducing apoptosis of T98G cells.

Table 1 summarizes the role of the receptor/ligand pairs in different cell lines contributed to the apoptosis induced by pDTP. Unlike HeLa cells that express the three extrinsic cell death receptors, the other cell lines lack the expression of at least one death receptor/ligand pair. The absence of the death receptors may contribute to the resistance of these tumor cells to the corresponding death ligands.

Western blot results show that the increasing inductive expression of TNFR2 and the up-and down-expression of TNFR1 over time (Figures $4 \mathrm{a}-\mathrm{c}$ ) are the common trends for

Table 1 The summary of the receptor/ligand pairs required for pDTP toxicity in different cell lines ( $\uparrow$ indicates increasing the cytotoxicity; $\downarrow$ indicates decreasing the cytotoxicity; - indicates little effect)

\begin{tabular}{lcccc}
\hline Cells & HeLa & MES-SA/Dx5 & T98G & A2780-cis \\
\hline mAbs & & & & \\
Anti-TNFR1 & $\uparrow$ & $\downarrow$ & - & - \\
Anti-TNFR2 & $\uparrow$ & $\downarrow$ & $\downarrow$ & $\downarrow$ \\
Anti-TNF- $a$ & $\downarrow$ & $\downarrow$ & $\downarrow$ & - \\
TNF-a & $\uparrow$ & - & $\uparrow$ & - \\
Anti-DR3 & $\uparrow$ & - & - & - \\
Anti-DR4 & $\uparrow$ & $\uparrow$ & $\uparrow$ & - \\
Anti-DR5 & - & $\downarrow$ & - & - \\
Anti-TRAIL & $\downarrow$ & - & $\uparrow$ & - \\
TRAIL & $\uparrow$ & - & - & - \\
Anti-CD95 & $\downarrow$ & - & $\uparrow$ & - \\
Anti-CD95L & $\uparrow$ & - & $\uparrow$ & $\downarrow$ \\
CD95L & $\downarrow$ & $\downarrow$ & & \\
\hline
\end{tabular}



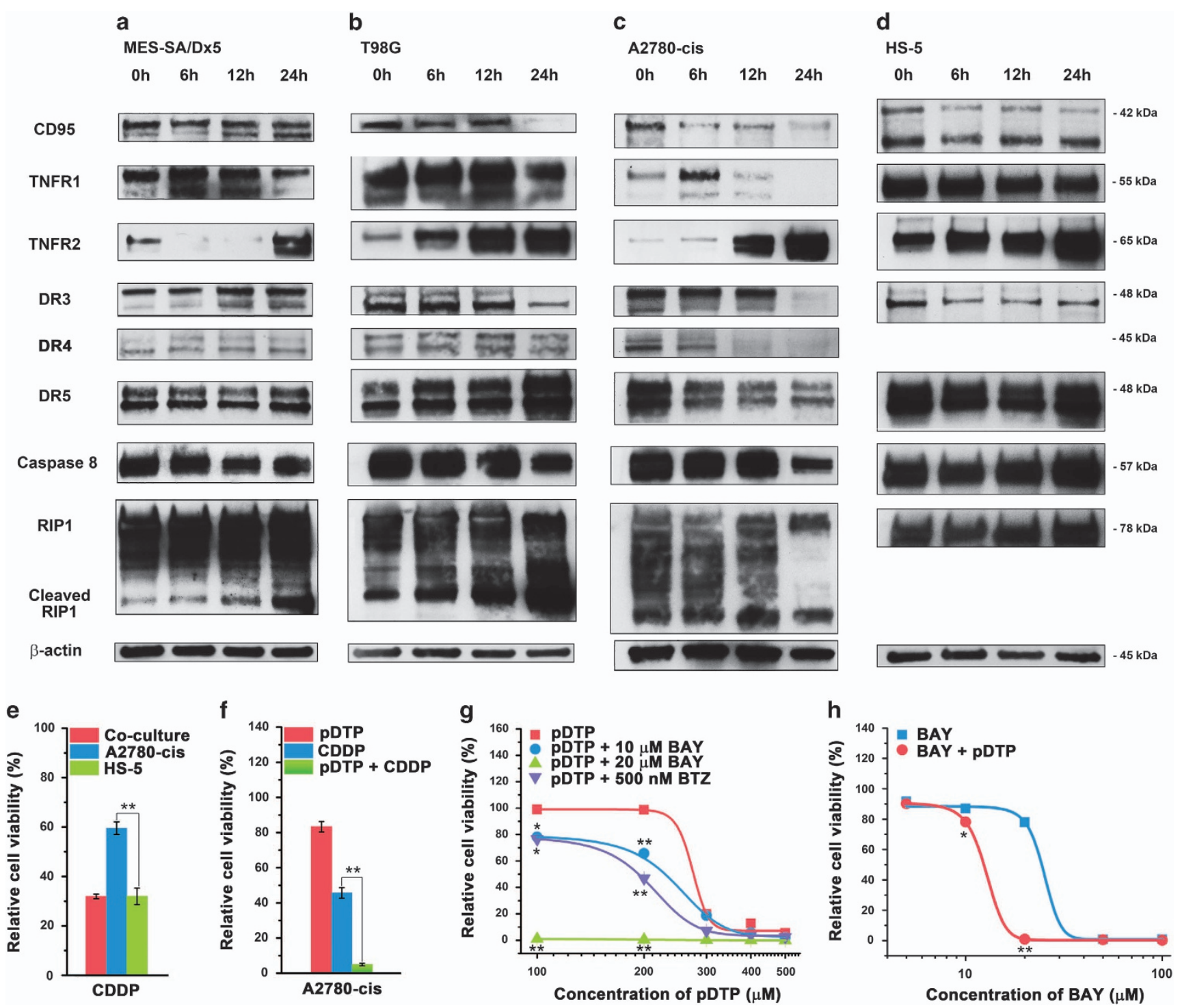

Figure 4 Pericellular D-peptide nanofibrils affect the expression of death receptors and selectively inhibit MDR cancer cells for combination therapy. Western blot shows change of relative amount of cell death receptors and two down-stream proteins over time in (a) MES-SA/Dx5, (b) T98G, (c) A2780-cis, or (d) HS-5 cells treated by pDTP. (e) Relative cell viability of the co-culture of A2780-cis and HS-5, A2780-cis, and HS- 5 cells incubated with cisplatin (CDDP) at the concentration of $6 \mu \mathrm{g} / \mathrm{ml}$ in DMEM. (f) Relative cell viability of A2780-cis cells incubated with $216 \mu \mathrm{g} / \mathrm{ml} \mathrm{pDTP,} 15 \mu \mathrm{g} / \mathrm{ml} \mathrm{CDDP}$, or the mixture of $216 \mu \mathrm{g} / \mathrm{ml} \mathrm{pDTP}$ and $15 \mu \mathrm{g} / \mathrm{ml}$ CDDP for $24 \mathrm{~h}$. Cells are pretreated with CDDP for $12 \mathrm{~h}$. Relative cell viability of HeLa cells incubated with (g) pDTP of different concentrations and 10 or $20 \mu \mathrm{M} \mathrm{BAY} 11-7085$ or $500 \mathrm{nM}$ BTZ; (h) BAY of different concentrations and $100 \mu \mathrm{M}$ pDTP. The incubation time is $48 \mathrm{~h}$. The initial number of cells is $1.0 \times 10^{4} /$ well. $n=3$. Data are shown as mean \pm S.D. ${ }^{*} P<0.05,{ }^{*} P<0.01$ by Student's $t$-test

these MDR cells incubated with pDTP. DR3 slightly increases on MEA-SA/Dx5, but decreases on T98G and varies on A2780-cis. DR5 exhibits little change on MES-SA/Dx5, increases on T98G, and decreases on A2780-cis (Figures $4 \mathrm{a}-\mathrm{c})$. These results indicate that the molecular crosstalk induced by DTP nanofibrils depends on cell types, partly due to the cell specific expressions of death ligands (Figures $3 b$ ). Meanwhile, pDTP results in changing the expression of caspase 8 and the fragmentation of RIP1 in these cell lines (Figures $4 a-c)$, further supporting the cell death largely via apoptosis. For HS-5 cells, pDTP results in little increase of TNFR2 and hardly affects expressions of other signaling molecules (e.g., TNFR1, caspase 8, or RIP1) (Figure 4d and Supplementary Figure 7a). HepG2 cells, a type of cancer cells being viable upon the pDTP treatment (Supplementary Figure $7 b$ ), exhibit decreasing the expression of TNFR2 (Supplementary Figures. 7c and d). These results establish ALP-generated DTP nanofibrils pleiotropically activating extrinsic cell death signaling as a general mechanism for triggering apoptosis of ALP-overexpressing cancer cells.

Combination of nanofibrils with CDDP or NF- $\mathrm{BB}$ inhibitors against MDR cancer cells. We compare the selectivity of cis-diamminedichloroplatinum(II) (CDDP), ${ }^{27}$ a clinical drug, with that of pDTP, and combine pDTP with CDDP or NF-kB inhibitors (e.g., BTZ ${ }^{28}$ or $\operatorname{BAY}(11-7085)^{29}$ ) for killing cancer cells. CDDP, unlike pDTP, inhibits cells with little selectivity (Figure $4 \mathrm{e}$ and Supplementary Figure 7e), even killing more 
HS-5 than to A2780-cis cells. pDTP turns the $\mathrm{IC}_{50}$ value of CDDP against $A 2780$-cis cells to an $\mathrm{IC}_{95}$ value (Figure $4 \mathrm{f}$ and Supplementary Figures $7 f$ and $g$ ), promising molecular nanofibrils for CDDP-based combination therapy. ${ }^{15}$ The presence of NF- $\kappa \mathrm{B}$ inhibitors (e.g., BTZ or BAY) considerably decreases the $I_{50}$ value of pDTP (Figures $4 \mathrm{~g}$ and $\mathrm{h}$ and Supplementary Figures $7 \mathrm{~h}$ and i) and even induces great cytotoxicity with lower concentration of pDTP (i.e., $3.6 \mu \mathrm{g} / \mathrm{ml}$, Supplementary Figure 7j) or with less incubation time (i.e., $2 \mathrm{~h}$, Supplementary Figure $7 \mathrm{k}$ ). These results agree with that DTP nanofibrils activate extrinsic cell death signaling and suggest the potential use of pDTP to enhance the efficacy and selectivity of NF- $k B$ inhibitors against cancer cells of solid tumors.

Peritumoral test in a murine model. We measure the tumor growth in xenograft tumor mice model with MES-SA/ Dx5 cells (Figure 5a and Supplementary Figure 8a) and find that the peritumoral treatment of pDTP significantly slows down the progression of tumor (i.e., seven times reduction comparing with the control group). The body weights of treated mice are comparable with those in the control group (Supplementary Figure 8b), and the skins covering and around tumor appear to be normal (i.e., without ulceration or sclerosis, Supplementary Figure $8 \mathrm{c}$ ) on every mice treated with pDTP, agreeing with DTP as innocuous monomers. ${ }^{7}$ In addition, pDTP hardly forms DTP nanofibrils in human serum (Supplementary Figures $8 \mathrm{~d}$ and e), suggesting low toxicity to in vivo. Thus, we conduct in vivo toxicity test in mice. The intravenous injection of pDTP has little adverse effect on mice, without changing body weight, spleen, thymus, and blood conditions (Figures $5 \mathrm{~b}$ and $\mathrm{c}$ and Supplementary Figures $9 \mathrm{a}-\mathrm{e}) . \mathrm{H}$ and $\mathrm{E}$ staining indicates that major organs (e.g., heart, spleen, kidney, liver, and lung) of the injected mice are normal (Figure 5d and Supplementary Figure 9f), further confirming low in vivo toxicity of pDTP.

\section{ALP generating nanofibrils as a multitargeting process} for apoptosis. The goal of cancer therapy is to kill cancer cells without harming normal cells. Although the generic differences between cancer and normal cells are rare, recent tissue-based map of human proteome ${ }^{42}$ indicates that overexpression of ALPs, one of the earliest tumor markers identified, ${ }^{31}$ is a generic difference between cancer and normal cells. Moreover, it is common for late stage cancers overexpress ALPs. ${ }^{43}$ However, ALP is 'undruggable'. Thus, the use of EISA as a process to generate nanofibrils as multifaceted, localized inducers for cell death signaling may be particularly valuable to address the problem of MDR in cancer therapy.

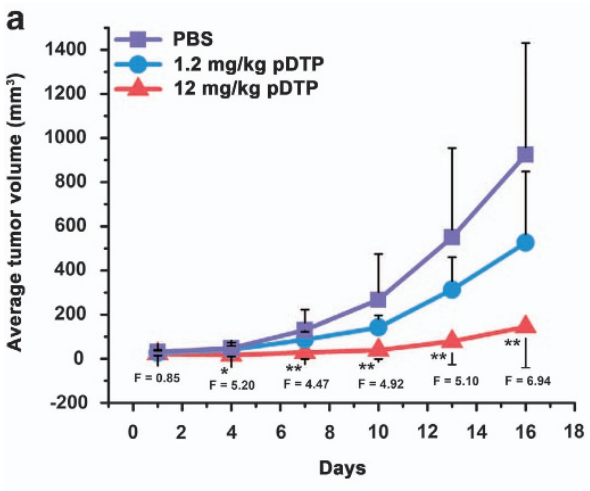

d
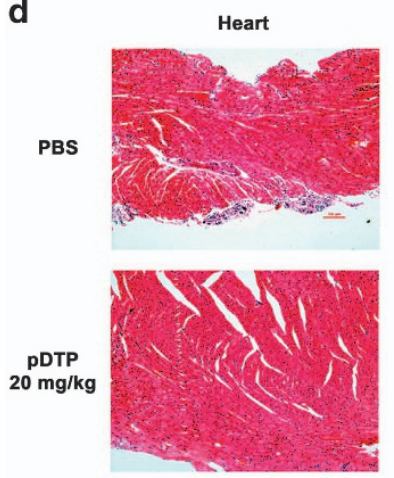

b

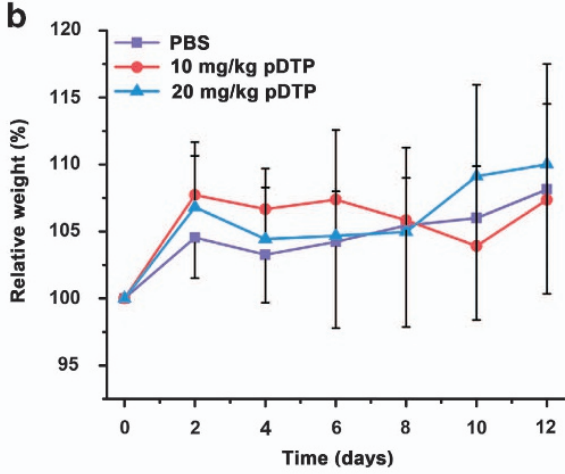

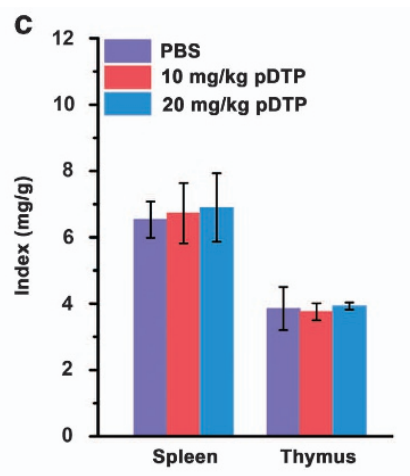

Figure 5 Pericellular D-peptide nanofibrils selectively inhibit MES-SA/Dx5 tumor on nu/nu mice. (a) Tumor progression curves of mice bearing MES-SA/Dx5 tumors. In all, $0.1 \mathrm{ml}$ of pDTP at $1.2 \mathrm{mg} / \mathrm{kg}, 12 \mathrm{mg} / \mathrm{kg}$, or just PBS buffer as control was injected subcutaneously and peritumorally in every 3 days (five doses, starting day 1 ). Data are shown as mean \pm S.D. (each group contains six mice). ${ }^{\star} P<0.05,{ }^{*} P<0.01$ by Student's $t$-test. $F$ values of every 3 days by Anova statistic with the critical value $F=3.68$. The change of the (b) body weights or (c) spleen or thymus index of nu/nu mice during the treatment. In all, $0.1 \mathrm{ml}$ of pDTP at $10 \mathrm{mg} / \mathrm{ml}, 20 \mathrm{mg} / \mathrm{ml}$, or just PBS buffer as control was injected intravenously (starting day 0), and then the body weights or spleen or thymus index of mice were tested. (d) Hematoxylin and eosin (H\&E) staining images of heart, spleen, kidney, liver, or lung from the nu/nu mice treated with $0.1 \mathrm{ml}$ of pDTP at $20 \mathrm{mg} / \mathrm{ml}$, or just PBS buffer as control by intravenous injection. The scale bar is $100 \mu \mathrm{m}$
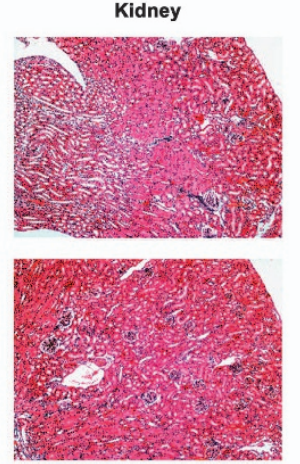
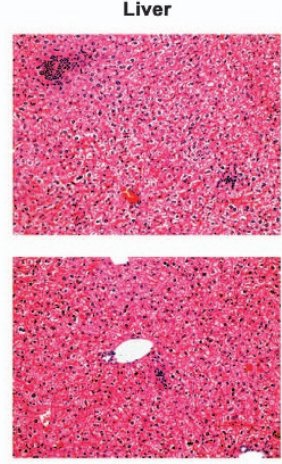
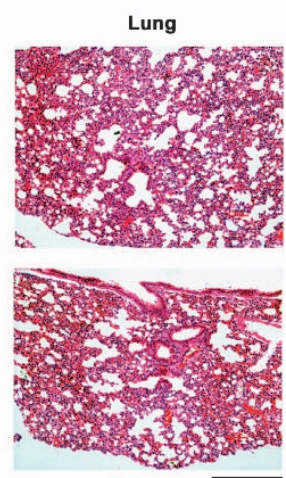
DTP combined with anti-TNFR1/2 mAbs has no effect on HeLa cells (Supplementary Figure 5a) since the assembly of DTP hardly localizes on cell surface without ALP catalysis. Anti-TNFR1 or anti-TNFR2 makes little difference on the viability of HS-5 treated with pDTP (Supplementary Figure $5 \mathrm{~b}$ ) because HS-5 expresses little ALP on cell surface (Figure $3 g$ ). In addition, unlike the case of HeLa cells treated with pDTP, western blot analysis of HeLa cells incubated with DTP itself, pDTP and L-Phe, or pDTP and ALP shows little change of the death receptors or down-stream proteins over time (i.e., little effect on the expression of TNFR1 and TNFR2). These results further confirm that the formation of DTP nanofibrils, a multiple step molecular process catalyzed by ALP in situ, is necessary for the selective inhibition of the cancer cells.

It is known that the co-incubation of a NF-kB inhibitor (e.g., cycloheximide) is necessary for TNF- $a$-induced apoptosis, ${ }^{35}$ an observation has led to the recognition of the difference between paracrine and juxtacrine signaling of TNF- $a{ }^{44}$ This work reports that hTNF- $a$ combined with pDTP induces cell death without NF- $k$ B inhibitors (Figure $2 b$ ), a strong evidence of DTP nanofibrils promoting the juxtacrine signaling. Because PLAP catalyzes the formation of DTP nanofibrils, the inclusion of exogenous hTNF- $a$ in the nanofibrils for juxtacrine signaling can occur during the self-assembly of DTP, which agrees with that more cells are dead upon the addition of hTNF- $a$. Moreover, the addition of anti-TNFR1 and anti-TNFR2 causes more death of HeLa cells incubated with pDTP, not only agreeing with that antibodies to TNF receptor can have TNF-like activity, ${ }^{45}$ but also suggesting that nanofibrils may crosslink/aggregate the antibody to convert an otherwise neutralizing antibody to an agonistic antibody. In addition, the combination of $\mathrm{pDTP}$ and NF- $k \mathrm{~B}$ inhibitors against cancer cells shows that PDTP enhances the efficacy of NF- $k B$ inhibitors (Figures $4 g$ and $h$ ). NF- $k$ B inhibitors also increase the inhibition ability of pDTP against cancer cells. These results further demonstrate DTP nanofibrils to bias $N F-\kappa B$ pathway for cell death, suggesting that it might be worthwhile to combine pDTP with other NF- $k$ B inhibitors for further elucidating the detailed mechanisms depending on specificity of NF-kB transcription factors.

Interestingly, the knock-down of either TNF- $a$, TRAIL, or CD95L receptors all rescues cell death $\sim 50 \%$, strongly suggesting crosstalk between all death receptor pathways at the level of receptor clustering and/or engagement. In addition, western blot analysis shows that DTP nanofibrils cause the reemergence of death receptors (especially TNFR1, TNFR2, and DR5) on siRNA knock-down cells (Figure $2 \mathrm{~g}$ ). This result indicates that, even if one kind of death receptors is knocked down, DTP nanofibrils can affect or interact with other receptors, regulate their down-stream signaling, and induce the re-emergence of silenced receptors, implying that the nanofibrils may counter cancer drug resistance ${ }^{13}$ due to downregulation of a death receptor. As the first mechanistic study on multitargeting by enzyme-triggered nanofibrils to result in apoptosis of cancer cells, this work also implies that the use of locally generated nanofibrils to present proapoptotic ligands (e.g., TNF-a, CD95L, and/or TRAIL) in a juxtacrine mode may lead a way to bringing back the early promises of proapoptotic ligands for cancer therapy.

\section{Materials and Methods}

Transmission electron microscopy (TEM). Before placing sample solution/gels on the grid ( $3 \mu \mathrm{l}$, sufficient to cover the grid surface), we glow discharge the carbon-coated grids to increase their hydrophilicity. About $10 \mathrm{~s}$ later, we place three large drops of $\mathrm{ddH}_{2} \mathrm{O}$ on parafilm to let the grid touch the water drops with the sample-loaded surface facing the parafilm, and then tilt the grid and gently absorb water from the edge of the grid using a filter paper. Immediately after rinsing, we place three large drops of uranyl acetate (UA) staining solution on parafilm to let the grid touch the staining solution drops with the sample-loaded surface facing the parafilm, and then tilt the grid and gently absorb the stain solutions from the edge of the grid using a filter paper. After drying the grid in air and it is ready for EM imaging, we examine the grid as soon as possible. ${ }^{46}$ Solutions and supplies: $2.0 \%$ (w/v) UA (prepare by dissolving $200 \mathrm{mg} \mathrm{UA}$ in $10 \mathrm{ml}$ of $\mathrm{dd}_{2} \mathrm{O}$. Add water to the tube containing UA, cover tube with foil and rotate in cold room for several hours till fully dissolved. Filter through a $0.22-\mu \mathrm{m}$ filter that has be pre-rinsed well with $\mathrm{ddH}_{2} \mathrm{O}$. Filtered stain stored at $4{ }^{\circ} \mathrm{C}$ in a foil-wrapped tube can be used for $>1$ year); filter strips (prepared by cutting Whatman 1 filter paper into small slivers); grids (400 mesh copper grids coated with continuous thick carbon film $~ 35 \mathrm{~nm}$ in thickness, purchased from Pacific Grid Tech. Co). We prepare samples by adding ALP $(5 \mathrm{U} / \mathrm{ml})$ to the solution of pDTP at concentration of $362 \mu \mathrm{g} / \mathrm{ml}$.

Cells culture. HeLa, T98G, HS-5, HepG2 cells are purchased from the American Type Culture Collection (ATCC, Manassas, VA, USA), MES-SA/Dx5 and A2780-cis cells from Sigma-Aldrich Co. (St. Louis, MO, USA), and HeLa-GFP cell from Cell Biolabs, Inc. (San Diego, CA, USA) HeLa, T98G, HeLa-GFP, HepG2 cells are propagated in minimum essential media (MEM, Invitrogen Life Technologies); HS- 5 cell is cultured in Dulbecco's modified Eagle's medium (DMEM, Invitrogen Life Technologies, Waltham, MA, USA); MES-SA/Dx5 cell is propagated in McCoy's 5A (Invitrogen Life Technologies); A2780-cis cell is propagated in RPMI-1640 medium (ATCC). A2780-cis is supplemented with $10 \% \mathrm{FBS}, 2 \mathrm{mM}$ glutamine, and $1 \mu \mathrm{M}$ cisplatin is necessary every 2-3 passages. The rest of the above cells are supplemented with $10 \%$ fetal bovine serum (FBS, Invitrogen Life Technologies) and $1 \%$ of antibiotics $(100 \mathrm{U} / \mathrm{ml}$ penicillin and $100 \mu \mathrm{g} / \mathrm{ml}$ streptomycin, Invitrogen Life Technologies). For the co-culture of cancer and normal cells, the cancer cells (HeLa-GFP, MES-SA/Dx5, T98G, A2780-cis) and normal cells (HS-5) are cultured in DMEM supplemented with $10 \%$ of FBS and $1 \%$ of antibiotics. All cells are incubated in a fully humidified incubator containing $5 \% \mathrm{CO}_{2}$ at $37^{\circ} \mathrm{C}$. For the $\mathrm{co}$ culture of two different cell lines, we mix same amount of two cells and incubate them in DMEM.

Cell viability assay. Cells in exponential growth phase are seeded in a 96-well plate at a density of $1 \times 10^{4}$ cells/well. The cells are allowed to attach to the wells for $4 \mathrm{~h}$ at $37^{\circ} \mathrm{C}, 5 \% \mathrm{CO}_{2}$. The culture medium is removed and $100 \mu \mathrm{l}$ culture medium containing compounds (immediately diluted from fresh prepared stock solution of $10 \mathrm{mM})$ at gradient concentrations ( $0 \mu \mathrm{M}$ as the control) is placed into each well. After culturing at $37{ }^{\circ} \mathrm{C}, 5 \% \mathrm{CO}_{2}$ for $24,48,72 \mathrm{~h}$, each well is added by $10 \mu \mathrm{l}$ of $5 \mathrm{mg} / \mathrm{ml}$ MTT ((3-(4, 5-dimethylthiazol-2-yl)-2, 5-diphenyltetrazolium bromide) ${ }^{47}$ and the plated cells are incubate at dark for $4 \mathrm{~h}$. One-hundred microliters $10 \%$ SDS with $0.01 \mathrm{M} \mathrm{HCl}$ is added to each well to stop the reduction reaction and to dissolve the purple. After incubation of the cells at $37^{\circ} \mathrm{C}$ for overnight, the $\mathrm{OD}$ at $595 \mathrm{~nm}$ of the solution is measured in a microplate reader (DTX 880 multimode detector). Data represent the mean \pm standard deviation of three independent experiments.

Live cell imaging. HeLa-GFP and HS- 5 cells in exponential growth phase are seeded in glass bottomed culture chamber at $1 \times 10^{5}$ cells/well $\left(5 \times 10^{4}\right.$ HeLa-GFP and $5 \times 10^{4} \mathrm{HS}-5$ cells per well). The cells are allowed for attachment for $24 \mathrm{~h}$ at $37^{\circ} \mathrm{C}, 5 \% \mathrm{CO}_{2}$. The culture medium is removed, and new culture medium containing pDTP at 216 or $362 \mu \mathrm{g} / \mathrm{ml}$ or f-pDTP at $493 \mu \mathrm{g} / \mathrm{ml}$ is added. After incubation for certain time (e.g., $24 \mathrm{~h}$ for pDTP or $4 \mathrm{~h}$ for f-pDTP), cells are stained with $1.0 \mu \mathrm{g} / \mathrm{ml}$ Hochst 33342 for $5 \mathrm{~min}$ at $37^{\circ} \mathrm{C}$ in dark. After that, cells are rinsed three times by PBS buffer, and then kept in PBS buffer for imaging.

Cell imaging with antibody staining. After incubating $1 \times 10^{5} \mathrm{HeLa}$ cells per glass bottomed culture chamber for $24 \mathrm{~h}$ at $37^{\circ} \mathrm{C}, 5 \% \mathrm{CO}_{2}$, the cells are treated with 216 or $362 \mu \mathrm{g} / \mathrm{ml}$ of pDTP for $24 \mathrm{~h}$. After three times rinse by PBS buffer, cells are $4 \%$ formaldehyde fixed $(10 \mathrm{~min})$ and then incubated in $1 \% \mathrm{BSA} / 10 \%$ normal goat serum $/ 0.3 \mathrm{M}$ glycine in $0.1 \%$ PBS-Tween for $1 \mathrm{~h}$ to permeabilize the cells and block non-specific protein-protein interactions. The cells are then incubated with the primary antibodies (e.g., anti-CD95, anti-TNFR1, anti-TNFR2, anti-DR3, anti-DR5 
mAbs) overnight at $+4{ }^{\circ} \mathrm{C}$. The secondary antibody (green) is Alexa Fluor 488 goat anti-rabbit lgG $(\mathrm{H}+\mathrm{L})(\mathrm{abcam})$ used at $2 \mu \mathrm{g} / \mathrm{ml}$ for $1 \mathrm{~h}$. Hochst 33342 is used to stain the cell nuclei (blue) at a concentration of $1.0 \mu \mathrm{g} / \mathrm{ml} .^{48}$ The fluorescent intensity in each image is analyzed using Image ${ }^{49}$

Knock-down HeLa cells. In a $3 \mathrm{~cm}$ petri dish, we seed $2 \times 10^{5} \mathrm{HeLa}$ cells in $2 \mathrm{ml}$ antibiotic-free normal growth medium supplemented with FBS and incubate the cells at $37{ }^{\circ} \mathrm{C}$ in a $\mathrm{CO}_{2}$ incubator for $24 \mathrm{~h}$ to make cells $60-80 \%$ confluent. We prepare two solutions, siRNA duplex solution (diluting $32 \mu \mathrm{l}$ siRNA duplex (Santa Cruz Biotechnology, Inc., Dallas, TX, USA) into $100 \mu \mathrm{l}$ siRNA transfection medium (Santa Cruz Biotechnology, Inc.)) and the dilute transfection reagent solution (dilute 6 or $32 \mu \mathrm{l}$ siRNA transfection reagent (Santa Cruz Biotechnology, Inc.) into $100 \mu$ siRNA transfection medium), and then mix gently the two solutions by pipetting the solution up and down and incubate the mixture $45 \mathrm{~min}$ at room temperature. After washing the cells once with $2 \mathrm{ml}$ of siRNA transfection medium, we immediately dilute the siRNA duplex mixture with $0.8 \mathrm{ml}$ transfection medium and overlay the mixture onto the washed cells. After incubating the cells $7-12 \mathrm{~h}$ (depending on the cell conditions) at $37^{\circ} \mathrm{C}$ in a $\mathrm{CO}_{2}$ incubator, $1 \mathrm{ml}$ of normal growth medium containing two times the normal serum and antibiotics concentration $(2 \times$ normal growth medium) is added without removing the transfection mixture (if toxicity is still a problem, we would remove the transfection mixture and replace with $1 \times$ normal growth medium). In all, 18-24 $\mathrm{h}$ later, we aspirate the medium and replace with fresh $1 \times$ normal growth medium, and then the cells are ready for western blot or cell viability assay after 72 more hours. ${ }^{50}$

Time-dependent western blot. Four of $10 \mathrm{~cm}$ petri dishes seeded $2 \times 10^{6}$ of HeLa, MES-SA/Dx5, T98G, A2780-cis, HS-5, or HepG2 cells onto each dish are prepared for the time-dependent western blotting experiment. After overnight incubation, we randomly choose three of them to be incubated with medium containing $300 \mu \mathrm{M}$ of pDTP, or just fresh medium. The other dish of cells is washed with PBS buffer for three times and scrapped from petri dish after adding $500 \mu \mathrm{l}$ cell lysis buffers, which represents the cell lysates at $0 \mathrm{~h}$. Similarly, we collect one dish of treated cell lysates at $6 \mathrm{~h}, 12 \mathrm{~h}, 24 \mathrm{~h}$, respectively, by using the same method. The collected cell lysates are mixed with $5 \mu$ of $100 \times$ proteinase inhibitor cocktail and then snap-frozen and thawed for three cycles to lyse the cells. The cell lysates are clarified by centrifugation at $12000 \times g$ for $20 \mathrm{~min}$ at $4{ }^{\circ} \mathrm{C}$ to remove the whole cells, nuclei, and large mitochondria. After quantification of proteins in cell lysates by using the Bradford reagent, the same amount of proteins for different time is mixed with the same volume of $2 \times$ Laemmli buffer before SDS-PAGE. After finishing the gel electrophoresis and transferring the proteins on the gels to the PVDF membranes for overnight, the membranes are incubated with primary antibodies (1:1000, all antibodies were obtained from Cell Signaling Technology, Danvers, MA, USA) for overnight. The membranes are then incubated with secondary antibodies (1:2000) for $1 \mathrm{~h}$, followed by the reaction with ECL solutions for $10 \mathrm{~min}$ and the final detection of proteins. ${ }^{51}$

Western blot of L-Phe or ALP co-incubated cells. Similar to the protocol of time dependent western blot, $2 \times 10^{6}$ of HeLa cells are seeded onto each $10 \mathrm{~cm}$ petri dish initially. After overnight incubation, three random dishes would be incubated with medium containing $300 \mu \mathrm{M}$ of pDTP and $5 \mathrm{mM}$ of L-phenylalanine (L-Phe). Another three random dishes would be incubated with medium containing $300 \mu \mathrm{M}$ of pDTP and $10 \mathrm{U} / \mathrm{ml}$ of alkaline phosphatase (ALP, Biomatik Corporation, Wilmington, DE, USA). Similarly, we collect the cell lysates at $0,6,12$, and $24 \mathrm{~h}$, respectively. After quantification of proteins in cell lysates by using the Bradford reagent, the same amount of proteins for different time is used for SDS-PAGE and western blotting.

In vivo tumor model with MES-SA/Dx5. The animal care facilities and programs of the Foster Animal Research Facility in Brandeis University meet the requirements of the law and $\mathrm{NIH}$ regulations. The animals are subjected to regular veterinary care on a routine basis. The animal experiments described in this study are performed according to the Guide for the Care and Use of Laboratory Animals published by the NIH. The nu/nu mice are purchased from Charles River Laboratories (Wilmington, MA). MES-SA/Dx5 cells are collected in exponential growth phase. In all, $100 \mu \mathrm{l}$ of MES-SA/Dx 5 cells suspension in complete culture medium at $5 \times 10^{7} \mathrm{cell} / \mathrm{m}$ is subcutaneously injected into the right flank of nu/nu mice. ${ }^{52}$ After 14 days of inoculation, mice bearing MES-SA/Dx5 tumor at average volume of $30 \mathrm{~mm}^{3}$ are randomly divided into three groups. Subcutaneous peritumoral injections are performed every 3 days for five doses. One group is treated with $100 \mu \mathrm{l}$ of pDTP at $3.6 \mathrm{mg} / \mathrm{ml}$ in PBS buffer; the other group is treated with $100 \mu \mathrm{l}$ of pDTP at $0.36 \mathrm{mg} /$ $\mathrm{ml}$ in PBS buffer; control group is treated with $100 \mu \mathrm{l}$ PBS buffer. Based on the average body weight of the mice $(22 \mathrm{~g})$ and the molar mass of pDTP $(723.23 \mathrm{~g} / \mathrm{mol})$, the dosages in gram per kilogram of body weight of pDTP on the mice were calculated as follow: $100 \mu \mathrm{l} \times 3.6 \mathrm{mg} / \mathrm{ml} \times 723.23 \mathrm{~g} / \mathrm{mol} / 22 \mathrm{~g}=12 \mathrm{mg} / \mathrm{kg} ; 100 \mu \mathrm{l} \times$ $0.36 \mathrm{mg} / \mathrm{ml} \times 723.23 \mathrm{~g} / \mathrm{mol} / 22 \mathrm{~g}=1.2 \mathrm{mg} / \mathrm{kg}$. The number of mice in each group is six. The statistical significance in relative tumor size between the control group and the group treated by $12 \mathrm{mg} / \mathrm{kg}$ of pDTP is examined by Student's $t$-test and Anova statistical analysis.

In vivo assessment of pDTP by intravenous injection. Similar to the protocol mentioned in nu/nu mice, we randomly divide mice into four groups: 10, 20, $50 \mathrm{mg} / \mathrm{kg}$ pDTP, and control group (PBS buffer). For each mouse, we would inject pDTP or PBS buffer every 3 days intravenously, and then measure the body weight of mice, organ index, or parameters of enzymes or proteins. In addition, we take $\mathrm{H}$ and $E$ staining images of heart, spleen, kidney, liver, and lung from the nu/nu mice. The number of mice in each group is six.

\section{Conflict of Interest}

The authors declare no conflict of interest.

Acknowledgements. We wish to thank Prof. Francis Chan for the suggestions on the mechanisms of cell death. We wish to thank Prof. Marcus Peter for providing the CD95L-KO HeyA8 cells. This work is partially supported by NIH (R01CA142746), the WM Keck Foundation, NSF (DMR-1420382), and International S\&T Cooperation Program of China (ISTCP, 2015DFA50310). JZ is an HHMI International Research Fellow.

\section{Author contributions}

BX conceptually designed the strategy for this study, provided intellectual input, supervised the studies, and wrote the manuscript. XD designed and performed experiments of chemical synthesis, in vitro, and in vivo operation, analyzed the experimental results, generated the Figures and wrote the manuscript. JZ helped designed the experiments and drew the scheme. HW and ZY performed the experiment with mice by intravenous injection. WZ, a biostatistician, helped the statistical analysis of the in vivo data. JS synthesized some compounds and YK screened several cell lines.

1. Fischer EH, Charbonneau H, Tonks NK. Protein tyrosine phosphatases - a diverse family of intracellular and transmembrane enzymes. Science 1991; 253: 401-406.

2. Krebs EG, Beavo JA. Phosphorylation-dephosphorylation of enzymes. Annu Rev Biochem 1979; 48: 923-959.

3. Lynch ED, Ostermeyer EA, Lee MK, Arena JF, Ji HL, Dann J et al. Inherited mutations in PTEN that are associated with breast cancer, Cowden disease, and juvenile polyposis. Am J Hum Genet 1997; 61: 1254-1260.

4. Blaskovich MAT. Drug discovery and protein tyrosine phosphatases. Curr Med Chem 2009; 16: 2095-2176.

5. Yang ZM, Gu HW, Fu DG, Gao P, Lam JK, Xu B. Enzymatic formation of supramolecular hydrogels. Adv Mater 2004; 16: 1440-1444.

6. Zhou J, Du X, Berciu C, He H, Shi J, Nicastro D et al. Enzyme-instructed self-assembly for spatiotemporal profiling of the activities of alkaline phosphatases on live cells. Chem 2016; 1 : 246-263.

7. Kuang Y, Du X, Zhou J, Xu B. Supramolecular nanofibrils inhibit cancer progression in vitro and in vivo. Adv Healthcare Mater 2014; 3: 1217-1221.

8. Kuang Y, Long MJC, Zhou J, Shi J, Gao Y, Xu C et al. Prion-like nanofibrils of small molecules (PriSM) selectively inhibit cancer cells by impeding cytoskeleton dynamics. J Biol Chem 2014; 289: 29208-29218.

9. Shi J, Du X, Yuan D, Zhou J, Zhou N, Huang Y et al. D-amino acids modulate the cellular response of enzymatic-instructed supramolecular nanofibers of small peptides. Biomacromolecules 2014; 15: 3559-3568.

10. Zhou J, Du X, Yamagata N, Xu B. Enzyme-instructed self-assembly of small d-peptides as a multiple-step process for selectively killing cancer cells. J Am Chem Soc 2016; 138 : 3813-3823.

11. Zhou J, Du X, Xu B. Regulating the rate of molecular self-assembly for targeting cancer cells. Angew Chem Int Ed 2016; 55: 5770-5775.

12. Feng Z, Wang H, Du X, Shi J, Li J, Xu B. Minimal C-terminal modification boosts peptide self-assembling ability for necroptosis of cancer cells. Chem Commun 2016; 52: 6332-6335. 
13. Wang $\mathrm{H}$, Feng Z, Wu D, Fritzsching KJ, Rigney M, Zhou J et al. Enzyme-regulated supramolecular assemblies of cholesterol conjugates against drug-resistant ovarian cancer cells. J Am Chem Soc 2016; 138: 10758-10761.

14. Kuang Y, Shi JF, Li J, Yuan D, Alberti KA, Xu QB et al. Pericellular hydrogel/nanonets inhibit cancer cells. Angew Chem Int Ed 2014; 53: 8104-8107.

15. Li J, Kuang Y, Shi J, Zhou J, Medina JE, Zhou R et al. Enzyme-instructed intracellular molecular self-assembly to boost activity of cisplatin against drug-resistant ovarian cancer cells. Angew Chem Int Ed 2015; 54: 13307-13311.

16. Yang ZM, Xu KM, Guo ZF, Guo ZH, Xu B. Intracellular enzymatic formation of nanofibers results in hydrogelation and regulated cell death. Adv Mater 2007; 19: 3152-3156.

17. Tanaka A, Fukuoka Y, Morimoto Y, Honjo T, Koda D, Goto M et al. Cancer cell death induced by the intracellular self-assembly of an enzyme-responsive supramolecular gelator. J Am Chem Soc 2015; 137: 770-775

18. Pires RA, Abul-Haija YM, Costa DS, Novoa-Carballal R, Reis RL, Ulijn RV et al. Controlling cancer cell fate using localized biocatalytic self-assembly of an aromatic carbohydrate amphiphile. J Am Chem Soc 2015; 137: 576-579.

19. Millan JL. Mammalian Alkaline Phosphatases: From Biology to Applications in Medicine and Biotechnology. John Wiley \& Sons: Weinheim, 2006.

20. Old LJ. Tumor necrosis factor (TNF). Science 1985; 230: 630-632.

21. Wiley SR, Schooley K, Smolak PJ, Din WS, Huang CP, Nicholl JK et al. Identification and characterization of a new member of the TNF family that induces apoptosis. Immunity 1995; 3: 673-682

22. Locksley RM, Killeen N, Lenardo MJ. The TNF and TNF receptor superfamilies: Integrating mammalian biology. Cell 2001; 104: 487-501.

23. Anklesaria P, Teixido J, Laiho M, Pierce JH, Greenberger JS, Massague J. Cell-cell adhesion mediated by binding of membrane-anchored transforming growth factor alpha to epidermal growth factor receptors promotes cell proliferation. Proc Natl Acad Sci USA 1990; 87: 3289-3293.

24. Watanabefukunaga R, Brannan $\mathrm{Cl}$, Copeland NG, Jenkins NA, Nagata S. Lymphoproliferation disorder in mice explained by defects in Fas antigen that mediates apoptosis. Nature 1992; 356: 314-317.

25. Kerr JFR, Wyllie AH, Currie AR. Apoptosis: a basic biological phenomenon with wide-ranging implications in tissue kinetics. Brit J Cancer 1972; 26: 239-257.

26. Straussman R, Morikawa T, Shee K, Barzily-Rokni M, Qian ZR, Du JY et al. Tumour microenvironment elicits innate resistance to RAF inhibitors through HGF secretion. Nature 2012; 487: 500-U118.

27. Rosenber. B, Vancamp L, Trosko JE, Mansour VH. Platinum compounds: a new class of potent antitumour agents. Nature 1969; 222: 385-386.

28. Richardson PG, Barlogie B, Berenson J, Singhal S, Jagannath S, Irwin D et al. A phase 2 study of bortezomib in relapsed, refractory myeloma. N Engl J Med 2003; 348: 2609-2617.

29. Lawrence T, Gilroy DW, Colville-Nash PR, Willoughby DA. Possible new role for NF-kappa B in the resolution of inflammation. Nat Med 2001; 7: 1291-1297.

30. Zhou J, Xu B. Enzyme-instructed self-assembly: a multistep process for potential cancer therapy. Bioconjugate Chem 2015; 26: 987-999.

31. Fishman WH, Inglis NR, Green S, Anstiss CL, Gosh NK, Reif AE et al. Immunology and biochemistry of regan isoenzyme of alkaline phosphatase in human cancer. Nature 1968; 219: 697-699.

32. Platani M, Goldberg I, Swedlow JR, Lamond Al. In vivo analysis of Cajal body movement, separation, and joining in live human cells. J Cell Biol 2000; 151: 1561-1574.

33. Fernley HN, Walker PG. Inhibition of alkaline phosphatase by L-phenylalanine. Biochem J 1970; 116: 543-544.

34. Zhu HJ, Fearnhead HO, Cohen GM. An ICE-like protease is a common mediator of apoptosis induced by diverse stimuli in human monocytic THP.1 cells. FEBS Lett 1995; 374: 303-308.

35. Tartaglia LA, Pennica D, Goeddel DV. Ligand passing: the 75-kDa tumor necrosis factor (TNF) receptor recruits TNF for signaling by the 55-kDa TNF receptor. J Biol Chem 1993 268: $18542-18548$

36. Tsuji Y, Watanabe N, Okamoto T, Tsuji N, Sasaki H, Akiyama S et al. Endogenous tumor necrosis factor functions as a resistant factor against hyperthermic cytotoxicity. Cancer Res 1992: 52: 6258-6262.
37. Haas $\mathrm{E}$, Grell M, Wajant $\mathrm{H}$, Scheurich $\mathrm{P}$. Continuous autotropic signaling by membraneexpressed tumor necrosis factor. J Biol Chem 1999; 274: 18107-18112.

38. Elbashir SM, Harborth J, Lendeckel W, Yalcin A, Weber K, Tuschl T. Duplexes of 21-nucleotide RNAs mediate RNA interference in cultured mammalian cells. Nature 2001; 411: 494-498.

39. Nair P, Lu M, Petersen S, Ashkenazi A. Apoptosis initiation through the cell-extrinsic pathway. Methods Enzymol 2014; 544: 99-128.

40. Vanden Berghe T, Kaiser WJ, Bertrand MJM, Vandenabeele P. Molecular crosstalk between apoptosis, necroptosis, and survival signaling. Mol Cell Oncol 2015; 2: e975093.

41. Tartaglia LA, Weber RF, Figari IS, Reynolds C, Palladino MA, Goeddel DV. The two different receptors for tumor necrosis factor mediate distinct cellular responses. Proc Natl Acad Sci USA 1991; 88: 9292-9296.

42. Uhlen M, Fagerberg L, Hallstrom BM, Lindskog C, Oksvold P, Mardinoglu A et al. Proteomics. Tissue-based map of the human proteome. Science 2015; 347: 1260419.

43. Gibson CJ, Britton KA, Miller AL, Loscalzo J. Out of the blue. N Engl J Med 2014; 370 : 1742-1748.

44. Ashkenazi A, Salvesen G. Regulated cell death: signaling and mechanisms. Annu Rev Cell Dev Biol 2014; 30: 337-356.

45. Engelmann H, Holtmann H, Brakebusch C, Avni YS, Sarov I, Nophar Y et al. Antibodies to a soluble form of a tumor necrosis factor (TNF) receptor have TNF-like activity. J Biol Chem 1990; 265: 14497-14504.

46. Tay FR, Gwinnett AJ, Wei SHY. The overwet phenomenon: A transmission electron microscopic study of surface moisture in the acid-conditioned, resin-dentin interface. Am J Dent 1996; 9: 161-166.

47. Fischer D, Li YX, Ahlemeyer B, Krieglstein J, Kissel T. In vitro cytotoxicity testing of polycations: influence of polymer structure on cell viability and hemolysis. Biomaterials 2003; 24: 1121-1131.

48. Hochbaum DR, Zhao Y, Farhi SL, Klapoetke N, Werley CA, Kapoor V et al. All-optical electrophysiology in mammalian neurons using engineered microbial rhodopsins. Nat Methods 2014; 11: 825-833.

49. French AP, Mills S, Swarup R, Bennett MJ, Pridmore TP. Colocalization of fluorescent markers in confocal microscope images of plant cells. Nat Protoc 2008;. 3: 619-628.

50. Venkatachalam K, Venkatesan B, Valente AJ, Melby PC, Nandish S, Reusch JEB et al. WISP1, a pro-mitogenic, pro-survival factor, mediates tumor necrosis factor-alpha (TNF-alpha)-stimulated cardiac fibroblast proliferation but inhibits TNF-alpha-induced cardiomyocyte death. J Biol Chem 2009; 284: 14414-14427.

51. Burnette WN. 'Western blotting': Electrophoretic transfer of proteins from sodium dodecy sulfate-polyacrylamide gels to unmodified nitrocellulose and radiographic detection with antibody and radioiodinated protein A. Anal Biochem 1981; 112: 195-203.

52. Gao XH, Cui YY, Levenson RM, Chung LWK, Nie SM. In vivo cancer targeting and imaging with semiconductor quantum dots. Nat Biotechnol 2004; 22: 969-976. c. published by Nature Publishing Group. This work is licensed under a Creative Commons Attribution 4.0 International License. The images or other third party material in this article are included in the article's Creative Commons license, unless indicated otherwise in the credit line; if the material is not included under the Creative Commons license, users will need to obtain permission from the license holder to reproduce the material. To view a copy of this license, visit http://creativecommons.org/licenses/by/4.0/

(C) The Author(s) 2017

Supplementary Information accompanies this paper on Cell Death and Disease website (http://www.nature.com/cddis) 